\section{Determinants of fertility in Ethiopia}

Dawit Getnet Ayele

School of Mathematics, Statistics and Computer Science, University of KwaZulu-Natal, Pietermaritzburg, Private Bag X01, Scottsville 3209, South Africa.

\section{Abstract}

Background: The most important elements to determine the rate of population growth is fertility. Fertility is the main element to affect the welfare of mother. The survival of a child can be affected by high fertility and shorter birth intervals. Methods: For this study, the linear mixed model was used to determine factors affecting fertility status of women in Ethiopia. The 2011 Ethiopian demographic and health survey data was used for this study.

Results: From the result, materials used for roof, wall and floor were found to have a significant relation to fertility level of women in the last five years. Moreover, family size and births in the last five years were found to have a significant relationship.

Conclusion: Significant variation in fertility level was observed among rural and urban residents of Ethiopia. To reduce the gap of fertility between rural and urban population, it is important to modernize different factors. These factors could be access to education, media, and providing employment opportunities in the modern economic sector. Besides this, it is important to develop and maintain the access of family planning services.

Keywords: EDHS, fertility, LMM, VC

\section{DOI: http://dx.doi.org/10.4314/ahs.v15i2.29}

Introduction To examine changes of a population over time, fertility Ethiopia, most families want to have large number of is the most important factor in population dynamics. It children. This is because, they are considered as an ecocontributes for the change and structure of the pop- nomic asset rather than liabilities. For most of rural arulation In sub-Sahatan countries, fertility rate is high eas, the children assist their parents in farming activities, compared to the rest of the world ${ }^{1-3}$. In Ethiopia the i.e., the economic importance of children are over lifesituation is similar, i.e., there is high fertility and rap- time. Similar to many countries in sub-Saharan Africa, id population growth rate.The country's population in having many children is considered as an advantage and 2013 was estimated to be more than 80 million $^{4}$. Ac- gift of God in a number of Ethiopian rural communicording to the 2011 Ethiopian demographic and health ties ${ }^{8,9}$.

survey, the total fertility rate at national level was 4.8

children per woman ${ }^{5}$. This value indicates that much Through years, the Ethiopian government developed effort should be made to attain the targets set in the na- several strategies to reduce fertility levels since 1993 tional population policy of Ethiopia by 2015. For high The plan of the government is to reduce total fertility fertility rate, the main reasons might be early age at first rate from the then 7.7 children per woman to 4.0 by marriage, desire for more children and $x$ contraceptive use. There are some of the major reasons nomic, demographic and geographic factors which behind such high fertility rate ${ }^{6,7}$.

\section{Corresponding author}

Dawit Getnet Ayele

School of Mathematics,

Statistics and Computer Science,

University of KwaZulu-Natal,

Pietermaritzburg, Private Bag X01,

Scottsville 3209, South Africa.

Email: ejigmul@yahoo.com/ ejigmul@gmail.com sample of 17,817 households was selected. To estimate at the national level, all data of the survey were weighted. Therefore, interviews were conducted with 9,096 15-49 aged women and 6,033 15-59 aged men. Therefore, the 2011 EDHS sample was designed to provide estimates for the health and demographic variables of interest for Ethiopia as a whole; urban and rural area of Ethiopia and 11 geographical areas ${ }^{4,5,11}$

\section{Variable of interes}

Response variables:- The outcome of interest is the births in last five years. This information is obtained by asking the mother how many live births she had in the past five years.

Independent variables:- The independent predictor variables consisted of baseline socio- economic, demographic and geographic variables, which were collected from each household. The socio-economic variable were the following: main source of drinking water; tim

$$
\mathrm{y}_{\mathrm{i}}=\mathrm{X}_{\mathrm{i}} \mathrm{\beta}+\mathrm{z}_{\mathrm{i}} \mathrm{u}_{\mathrm{i}}+\mathrm{z}_{\mathrm{i}, \mathrm{i}}=1, \mathrm{Z}_{2}, \ldots, \mathrm{k}
$$

where

Fis a $p \times 1$ vector of fixed effects;

$\boldsymbol{y}_{i}$ is an $n \times 1$ vector of observed responses;

$\boldsymbol{X}_{i}$ is an $n \times p$ design matrix associated with $\beta$

$\boldsymbol{u}_{i}$ is a $q_{i} \times 1$ vector of independent random effects with a $\mathbb{N}\left(0_{i} I_{q_{i}} \sigma_{i}^{2}\right)$ distribution;

$\boldsymbol{Z}_{i}$ is an $n \times q_{i}$ design matrix associated with $\boldsymbol{u}_{i}$, where $\boldsymbol{u}_{i \mathbf{i}}$ is a $q_{i} \times 1$ vector of independent random variables with a $\mathrm{N}\left(0, \sigma_{\mathrm{i}}^{2}\right)$ distribution, $\ell=1,2, \ldots, \mathbb{k}$,

$\varepsilon_{i}$ is an $n \times 1$ vector of random errors from a $\mathrm{N}\left(0, \boldsymbol{I}_{\mathrm{g}} \sigma_{a}^{2}\right)$, and $\boldsymbol{u}_{\mathrm{i}}$ and $\varepsilon_{\mathrm{i}}$ are mutually independent.

The random effects vectors $\boldsymbol{u}_{i}$ are assumed to be independent and normally distributed with mean vector

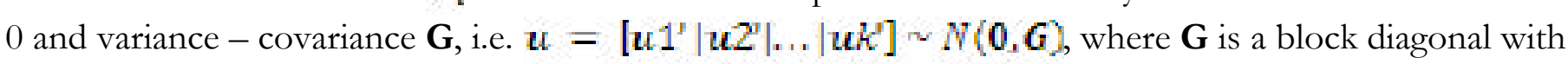
the ith block $\sigma_{i \mathrm{i}}^{2} \mathbf{I}_{\mathrm{qi}}$, and the error vectors si are assumed to be independent and normally distributed with mean vector $\mathbf{0}$ and variance - covariance matrix $\boldsymbol{R}_{\tilde{v}}$, i.e. $\boldsymbol{\varepsilon}_{\mathfrak{i}} \sim \mathbb{N}\left(\mathbf{0}, \mathbf{R}_{\mathrm{i}}\right)$, for i $=1,2, \ldots$, k. Here, $\mathbf{G}$ and $\boldsymbol{R}_{\tilde{i}}$ are $q \times q$ (where, $q=q_{1}+q_{2}+\ldots+q_{n_{2}}$ ) and $n \times n$ matrices respectively. Under the assumption of normality and independence for $u_{i}$ and $\varepsilon_{\xi}$, the marginal distribution of the response $y_{i}$ is normal with

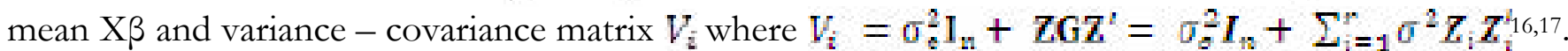
Estimation of $\sigma_{a}^{2}$ and the $\sigma_{i}^{2}$ is done using either the analysis of variance (ANOVA) method, or the maximum likelihood and the restricted/residual maximum likelihood methods under the assumption of normality and independence for $\boldsymbol{u}_{i}$ and $\boldsymbol{\varepsilon}_{\mathrm{i}}$. The methods are described in the next section. Further literature for linear mixed model can be found in different books ${ }^{13,14,16-24}$. 
The results for the random effects that the effect of graphic and geographic factors on fertility status of cluster was significant ( $\mathrm{p}$-value $=0.03$ ). Therefore, the women was investigated. To obtain the required result, estimated value 0.06 was found to be significant. linear mixed model approach was used. The result is presented in Table 1. The null model likelihood ratio The usual model error assumptions for these modtest (LRT) for the analysis is given by Chi-square val- els were checked using the residual plots in Figures 1. ue 28.08 (P-value $<0.0001$ ). This is highly significant From the figures, the first plot is of the predicted values for this model, indicating that the compound symme- against studentized residuals. These plots show that the try (CS) covariance matrix is preferred to the diagonal studentized residuals vary between -1 and 1 . The next matrix of the ordinary least squares null model. From two plots are a histogram and q-q plot of studentized the result it was observed that all socio-economic, de- residuals, and intended to show the normality of the mographic and geographic factors were found to have studentized residuals. These plots show that the usual significant effect on the fertility status of the mother assumptions of the linear mixed model were not seriously violated by the data.
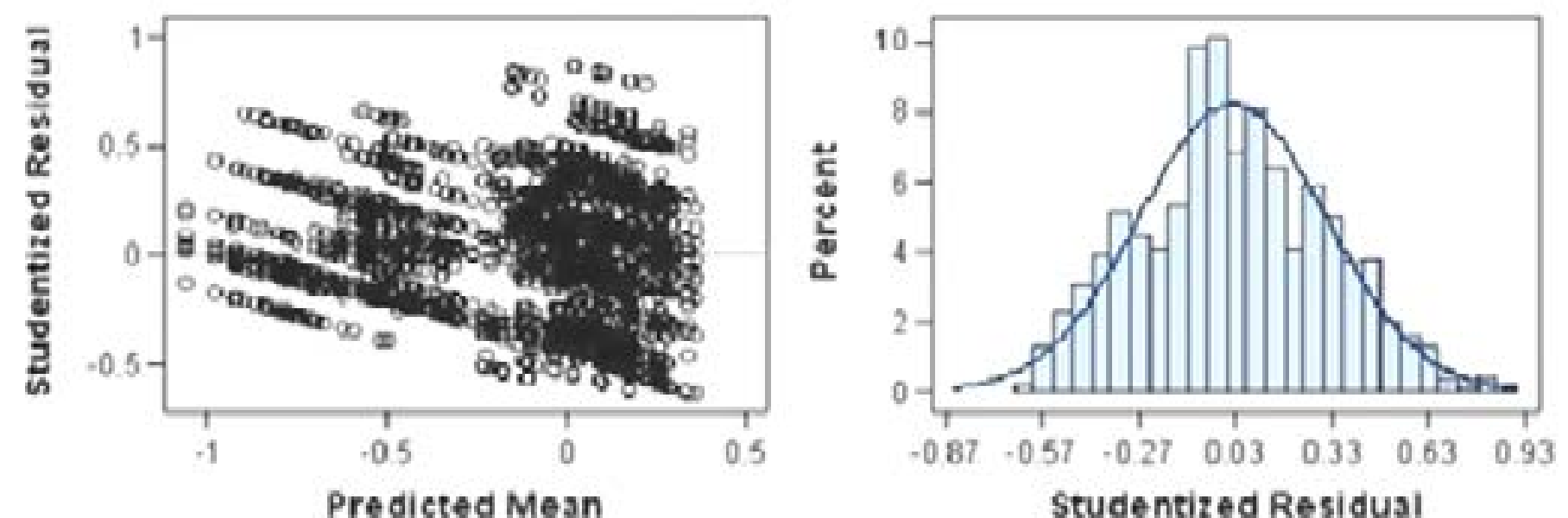
Studentized Residuai

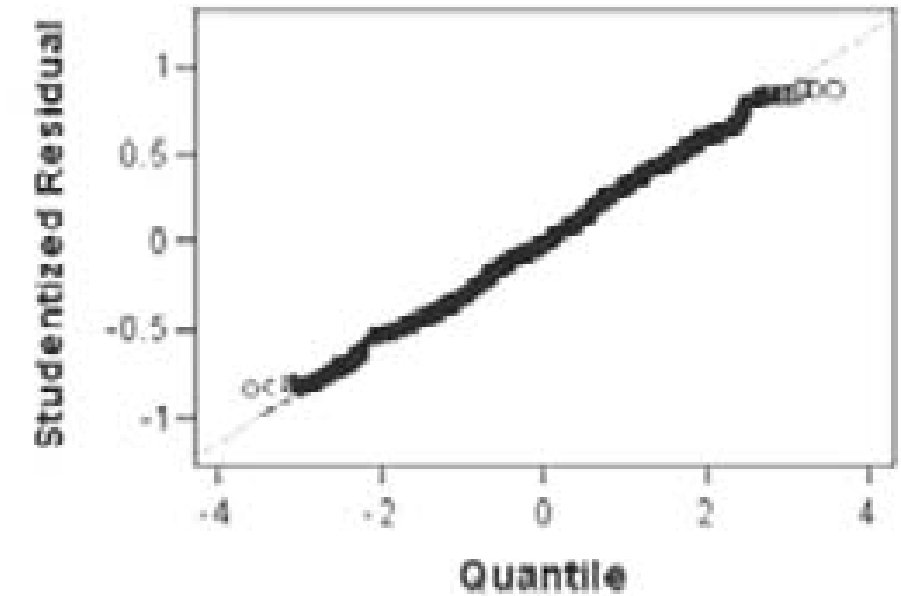

Figure 1: Plots of studentized Residuals

Table 1 shows that fertility status of a woman is dif- fertility rate was observed in Addis Ababa administraferent among the eleven administrative regions. As the tive region (-0.83), followed by Harari, Benishangul-Guresult indicates, the highest fertility is found in Somali muz, Amhara, Oromiya, SNNP, Gambela and Afar reregion $(10.9 \%)$ followed by Dire Dawa administrative gions compared to Tigray region. Similarly, women who region $(0.6 \%)$ compared to Tigray region. The lowest live in rural area have $4.9 \%$ higher fertility compared to women who live in urban areas.
Table 1: Socio-economic, demographic and geographic factors

\begin{tabular}{|c|c|c|c|c|c|}
\hline Effect & Estimate & $\mathrm{t}$ Value & $P$-value & Lower & Upper \\
\hline Intercept & 0.599 & 18.57 & $<.0001$ & 0.536 & 0.662 \\
\hline \multicolumn{6}{|l|}{ Region (Ref. Tigray) } \\
\hline Affar & -0.012 & -1.13 & 0.2568 & -0.032 & 0.008 \\
\hline Amhara & -0.038 & -5.21 & $<.0001$ & -0.052 & -0.024 \\
\hline Oromiya & -0.029 & -3.87 & 0.0001 & -0.043 & -0.014 \\
\hline Somali & 0.109 & 9.93 & $<.0001$ & 0.087 & 0.130 \\
\hline Benishangul-Gumuz & -0.055 & -6.73 & $<.0001$ & -0.071 & -0.039 \\
\hline SNNP & -0.027 & -3.16 & 0.0016 & -0.043 & -0.010 \\
\hline Harari & -0.071 & -7.86 & $<.0001$ & -0.089 & -0.054 \\
\hline Gambela & -0.016 & -11.40 & $<.0001$ & -0.088 & -0.012 \\
\hline Addis Ababa & -0.083 & -8.25 & $<.0001$ & -0.103 & -0.063 \\
\hline \multirow{2}{*}{\multicolumn{6}{|c|}{ Place of residence (Ref. Urban) }} \\
\hline & & & & & \\
\hline Rural & 0.049 & 7.88 & $<.0001$ & 0.038 & 0.062 \\
\hline \multicolumn{6}{|l|}{ Religion (Ref Traditional) } \\
\hline Catholic & -0.118 & -5.62 & $<.0001$ & -0.159 & -0.077 \\
\hline Muslim & 0.017 & 1.05 & 0.2927 & -0.014 & 0.048 \\
\hline Orthodox & -0.047 & -2.92 & 0.0035 & -0.078 & -0.015 \\
\hline Protestant & -0.019 & -1.21 & 0.2271 & -0.049 & 0.012 \\
\hline \multicolumn{6}{|c|}{ Educational level (Ref. Higher education) } \\
\hline Secondary & 0.028 & 4.74 & $<.0001$ & 0.033 & 0.079 \\
\hline No education & 0.073 & 8.41 & $<.0001$ & 0.056 & 0.090 \\
\hline Primary & 0.056 & 3.29 & 0.0010 & 0.011 & 0.044 \\
\hline \multicolumn{6}{|c|}{ Main source of drinking water (Ref. Unprotected) } \\
\hline Protected water & -0.026 & -5.88 & $<.0001$ & -0.034 & -0.017 \\
\hline Tap Water & -0.034 & -7.08 & $<.0001$ & -0.044 & -0.025 \\
\hline \multicolumn{6}{|l|}{ Toilet facility (Ref. Pit latrine) } \\
\hline Flush toilet & -0.027 & -3.00 & 0.0027 & -0.044 & -0.009 \\
\hline No facility & 0.039 & 0.88 & 0.3794 & -0.049 & 0.129 \\
\hline \multicolumn{6}{|c|}{ Type of cooking fuel (Ref. Wood charcoal) } \\
\hline Electricity & 0.028 & 1.87 & 0.0615 & -0.001 & 0.058 \\
\hline Gas/LPG & -0.043 & -4.20 & $<.0001$ & -0.063 & -0.023 \\
\hline No food to cook & 0.234 & 4.71 & $<.0001$ & 0.137 & 0.331 \\
\hline \multicolumn{6}{|l|}{ Main floor material (Ref. wood and } \\
\hline Carpet & -0.048 & -2.23 & 0.0254 & -0.091 & -0.006 \\
\hline Cement & -0.068 & -3.41 & 0.0007 & -0.107 & -0.029 \\
\hline Natural floor & -0.032 & -1.67 & 0.0944 & -0.070 & 0.006 \\
\hline \multicolumn{6}{|c|}{ Main roof material (Ref. Thatch/plastic/wood) } \\
\hline Finished roofing & -0.025 & -5.89 & $<.0001$ & -0.033 & -0.017 \\
\hline No roof & 0.079 & 7.27 & $<.0001$ & 0.058 & 0.100 \\
\hline \multicolumn{6}{|l|}{ Main wall material (Ref. No walls) } \\
\hline Cane/Wood etc. & 0.110 & 9.23 & $<.0001$ & 0.087 & 0.134 \\
\hline Finished walls & 0.161 & 12.10 & $<.0001$ & 0.135 & 0.188 \\
\hline Family size & -0.004 & -3.71 & 0.0002 & -0.006 & -0.002 \\
\hline Age of respondents at first sex & 0.015 & 31.49 & $<.0001$ & 0.014 & 0.016 \\
\hline Current age of respondents & -0.021 & -71.20 & $<.0001$ & -0.021 & -0.020 \\
\hline Time to collect water & 0.0041 & 1.79 & 0.0742 & $-1.11 \mathrm{E}-6$ & 0.0024 \\
\hline
\end{tabular}

The association between fertility in the last five years ity $(7 \%)$ followed by primary $(5 \%)$ and secondary $(2 \%)$ and religion shows that muslim women have $1.7 \%$ high- compared to women who attended higher education. er fertility compared to women with traditional beliefs. From the result, it was found that main source of waBut, women who are Catholic $(-0.118)$ have lowest ter and births in the last five years were found to have fertility followed by Orthodox (-0.047) and Protestant significant relation. As the result indicates, women who $(-0.019)$ compared to traditional religion. On the other use tap water have lowest fertility $(-0.034)$ followed by hand, women who have no education have higher fertil- protected water (-0.026) compared to women who use 

$23.4 \%$ ) have more children compared to women who use wood/charcoal for cooking. Similarly, women who used electricity for cooking $(2.8 \%)$ have more children compared to women who use wood/charcoal for cooking.

Regarding materials used for roof, wall and floor, from the result it was found that births in the last five years were found to have significant relation to material used for wall, roof and floor. This result is presented in Table 1. Furthermore, from the result it were found that family size and births in the last five years found to have significant relationship. Therefore, as family size in the household increases, births for last five years decrease by $0.4 \%$. But, as age of respondents at first sex increases, births in the last five years increase by $1.5 \%$. In contrary, for one year increase in the current age of respondent, the birth in the last five years decreases by $2.1 \%$

\section{Discussion}

The most important challenge is how to manage with ageing and possible population declines in most countries. In addition to this, it is important to assist programmes to reduce the rate fertility in countries where population growth continues to be high. Therefore, to maintain the fertility status of Ethiopia, it is important to increase age at first marriage. This can be achieved by enhancing women's status through providing them with better employment and educational opportunities $^{27,28}$. Besides this it is important to expand family planning services and information, communication and education to limit family size of the country. Because of this, the government program so that fertility would decline over time. At national level, fertility has shown a declining trend. But, fertility is still high to some regions. Therefore, from the result, it was observed that there are clear regiona differences in fertility levels and trends in Ethiopia.

From the result it was observed that some of the regions like Addis Ababa have very low fertility which is below replacement level of fertility. But, other regions like Oromiya, Somali, and SNNP regions have high total fertility rates. For this high fertility, there might be cultural and traditional barriers to effectively utilize modern birth control methods. Other factors could be low status of women and gender inequality including poor health service coverage. For some regions, it was difficult to implement programs that would contribute to fertility transition in each region. Besides regions, high fertility was observed in rural areas than urban areas. Religion also has influence on the status of fertility since Muslim respondents have more children as compared to others. Moreover, women who are less educated have more kids. Based on the economic statu

of the woman, women who have better facilities tend to have lower fertility. This implies that in areas where traditional social and economic systems continue, the level of fertility is still high. Therefore, for essential change in fertility level, it is important to breakdown the traditional social system. In addition to this, it is important to have transformation of the economy. These changes have to be implemented from changes in the family system, i.e., the persistence of agrarian economy hat favours large family size. These families maintained high fertility levels.

\section{Conclusion}

Therefore, from the result, significant variation in fertility level was observed among rural and urban residents of Ethiopia. To reduce the gap of fertility between rural and urban population, it is important to modernizedifferent factors. These factors could be access to education, media, and providing employment opportunities in the modern economic sector. Besides this, it is mportant to develop and maintain the access of family planning services.

\section{References}

Caldwell, J.C. and P. Caldwell, The CulturalContex of High Fertility in sub-Saharan Africa Population and Development Review, 1987. 16(3): p. 409-437.

2. Hinde, A. and A. Mturi, Recent Trends in Tanzanian Fertility. Population Studies, 2000. 54(2): p. 177-191.

3. Romaniuk, A., Increase in Natural Fertility during the Early Stages of Modernization:Evidence from an African Case Study, Zaire. Population Studies, 1980 34(2): p. 293-310.

4. CSA, Central Statistics Agency of Ethiopia and ORC Macro: Ethiopia demographic and health survey 2011. Addis Ababa and Calverton, MD: Central Statistics Agency and ORC Macro. 2012

5. CSA, Central Statistics Agency of Ethiopia and ORC Macro: Ethiopia demographic and health survey 2005 Addis Ababa and Calverton, MD: Central Statistics
Agency and ORC Macro. [http://www.measuredhs. com/pubs/pdf/FR179/FR179.pdf]. 2006

6. Assefa, H., An Overview of the Determinants of

High Fertility in Ethiopia. Ethiopian Journal of Development Research, 1992. 14(2): p. 1-30.

7. Gibson M and M. R, Labour Saving Technology and Fertility Increase in Rural Africa. Current Anthropology, 2002. 43: p. 213-222

8. Desta, K. and G. Seyoum, Family System in Ethiopia. In: Hand Book on Population and for Secondary School Teachers in Ethiopia. Edited by Seyoum Gebreselassie and Markos Ezra DTRC and ICDR, Addis Ababa. Family line Education 1998.

9. Bairagi, R., Effect of Sex Preference on Contraceptive Use, Abortion and Fertility in Matlab, Bangladesh. International Family Planning perspectives, 2001. 27(3): p. 137-143.

10. National Population Office, National Population Policy of Ethiopia, Addis Ababa. 1993.

11. CSA, Central Statistics Agency of Ethiopia an ORC Macro: Ethiopia demographic and health surve 2000. Addis Ababa and Calverton, MD: Central Statistics Agency and ORC Macro. 2000.

12. Henderson, C.R., Estimation of variance and covariance components. Biometrics, 1953. 9: p. 226 - 252 3. Henderson, C.R., et al., Estimation of environmental and genetic trends from records subject to culling. Biometrica, 1959. 15: p. 192 - 218

14. Henderson, $C R$, et al, The estimation of the environmental and genetic trends from records subject to culling. Biometrics, 1959. 15: p. 192 - 218.

15. Davis, C.S., Statistical Methods for the Analysis of Repearted Measurements2002, New York: Springer.

16. Zewotir, T. and J.S. Galpin, Influence diagnostic for models. Journal of Data Science, 2005. 3: p. 153-177.

17. Zewotir T. and JS Galpin, Evaluation of linear mixed model case deletion diagnostic tools by Monte Carlo simulation. Communication in Statistics - SimuComputation, 2006. 35: p. 645 - 682.

8. Bijleveld, C.C.J.H. and L.J.T.V.d. kamp, Longitudinal Data Analysis1998: SAGE, London

19. Demidenko, E., Mixed Models: Theory and Applications2004, New Jersey: Wiley-Interscience.

20. Demidenko, E. and T.A. Stukel, Influence analysis or linear mixed-effects models. Statistics in Medicine, 2005. 24(6): p. 893-909.

1. Fitzmaurice, L.N. M., and W.J. H., Applied Longitudinal Analysis2004, New Jersey: John Wiley.

22. Hockihg, R.R., J.W. Green, and R.H. Bremer, Varance components estimation with model-based diagnositics. Technomestrics, 1989. 31: p. 227-239.

23. John Neter, W. Wasserman, and M.H. Kutner, Applied Linear Statistical Models. 3rd ed1974: IRWIN.

24. Liang, K.Y. and S.L. Zeger, Longitudinal data analysis using generalized linear models. Biometrika, 1986. 73: p. 13-22.

25. Searle, S.R., G. Casella, and C.E. McCulloch, Variance components1992: New York: Wiley.

26. Verbeke, G. and G. Molenberghs, Linear Mixed Models for Longitudinal Data2000, New York: Spring-

27. Chesnais, J.-C., Comment: A March Toward Population Recession. Population and Development Review (New York), Supplement, 2001: p. 255-259.

28. Guengant, J.-P. and M. John, Impact of the proximate determinants on the future course of fertility in sub-Saharan Africa. Workshop on "Prospects for Fertility Decline in High Fertility Countries. Population Division, United Nations, New York, July 9-11, 2001, 2001. 